\title{
Correlation between the Consumption Frequency of Sugar Sweetened Beverages with Serum Triglyceride Levels in Female Adolescents
}

Received, 29 November 2018 Accepted, 03 January 2019

Link to DOI:

10.25220/WNJ.V02.i2.0007

Journal Website: www.worldnutrijournal.org

Laga Patriantoro ${ }^{1}$, Yoga Devaera², Saptawati Bardosono ${ }^{3}$, Khalida Fauzia ${ }^{1}$, Meirina Khoirunnisa ${ }^{1}$, Dyah Saptarini ${ }^{1}$

1. Faculty of Medicine, Universitas Indonesia

2. Department of Pediatric, Faculty of Medicine, Universitas Indonesia, Cipto Mangunkusumo Hospital, Jakarta

3. Department of Nutrition, Faculty of Medicine, Universitas Indonesia, Cipto Mangunkusumo Hospital, Jakarta

\section{Abstract}

Introduction The prevalence of overweight and obesity in adolescence increases significantly from year to year particularly in Depok City, Indonesia. Consumption of sugar-sweetened beverages is one of the causes. Excess triglyceride levels are one of the risk factor for metabolic syndrome and cardiovascular disease. Consumption frequency of sugar-sweetened beverages is associated with increased serum triglyceride levels.

Methods This study used a cross-sectional design involving 47 subjects recruited through the consecutive sampling method. The consumption frequency of sugarsweetened beverages is taken by the semi quantitative FFQ method. Samples of serum triglyceride levels were taken from venous blood and measured using enzymatic methods.

Results Forty-seven female adolescence subjects, age ranged 15-17 years old, finished the study protocol. The result showed that there is a significant positive correlation with very strong degrees $(p=<0.001, r=0.88)$ between the consumption frequency of sugar-sweetened beverages with serum triglyceride levels.

Conclusion There is a significant positive correlation with very strong degrees between the consumption frequencies of sugar-sweetened beverages with serum triglyceride levels in our subject.

Keywords overweight, female adolescence, sugar-sweetened beverages, triglyceride

Introduction
The prevalence of overweight and obesity in adolescence increases significantly from year to year. According to Riset Kesehatan Dasar (Riskesdas) Indonesia 2013 shows nationally that the problem of overweight in adolescents aged 1315 years in Indonesia is $10.8 \%$, which consists of $8.3 \%$ overweight, and $2.5 \%$ obesity. ${ }^{1}$ In addition, in Indonesia it was also found an increase in the 
incidence of overweight from $1.4 \%$ in 2007 to $7.3 \%$ in 2013 in adolescents over the age of 15 years. Based on the 2013 Riskesdas data for the city of Depok, the prevalence of adolescents aged 13-15 years who are overweight is $12.1 \%$ while those who are obese are 1.5\%. For adolescents aged 16-18 years, the prevalence of obesity is $17.0 \%$ and obesity is $3.8 \%{ }^{1}$

The trend of increasing prevalence of overweight and obesity is one of which can be caused by ignorance in the selection of drinks. Sugar-sweetened beverages are beverages that are given simple sugar additions during the production process that can add energy content, but have a small amount of other nutrients. ${ }^{2}$ Among all age groups, the age group of teens is the one who consumes the most sugar-sweetened beverages. In adolescents aged 12-19 years in America as many as 65.4\% consume soft drinks, sweetened at least 1 time per day. ${ }^{3}$ Additional sugars from sugar-sweetened beverages also contribute significantly to the total energy. From a study conducted by SanchezPimienta stated that sugar-sweetened beverages contribute $13.5 \%$ to total energy in adolescents. ${ }^{4}$

Female adolescence need special attention because they will become mothers who will conceive and give birth and it has been known that an abnormal increase in triglyceride levels in the first trimester has a significant correlation with gestational hypertension, preeclampsia, induction of preterm birth, and fetal weight greater than gestational age. ${ }^{5}$

Triglycerides are one form of fat deposits in the body and are used as an energy source for various metabolic processes and constituents of cell membranes. The recommended triglyceride level for adolescents is $<130 \mathrm{mg} / \mathrm{dL} .{ }^{6}$ Frequent consumption of sweetened soft drinks can increase triglyceride levels through increased of de novo lipogenesis. ${ }^{7}$

Sugar-sweetened beverages contain a high amount of calories. Calories that are high enough from sweeteners with a low nutrient content can result in individuals at high risk for body fat accumulation. ${ }^{8}$ This increase in body fat mass can occur in two ways, namely an increase in the size of mature adipocytes (hypertrophy) as a result of accumulation excessive triglycerides during periods of energy imbalance and the addition of adipocyte cell counts (hyperplasia) as a result of immature adipocyte cells into more cells. ${ }^{9,10}$
The study conducted by Maria et al 2015 in children aged 8-15 years in America found high triglyceride levels in children who often consume sugar-sweetened beverages. ${ }^{11}$ On the other hand A study conducted by Kosova et al in 2013 in America stated that there was no significant relationship between the consumption of sugar-sweetened beverages and triglyceride levels in children aged 311 years. ${ }^{12}$ Thus, the purpose of the current study is to researchers to conduct research on the frequency of consumption of sugar-sweetened beverages with serum triglyceride levels in female adolescents.

\section{Methods}

\section{Subjects}

Forty seven female students, age ranged between 1517 years old, in some high school in Depok City, Indonesia were recruited. Subjects and subject's parents who were willing to take part in the study were asked to sign an informed consent. In subjects and parents of research subjects who signed an informed consent, interviews were conducted to obtain characteristic data, weight and height to obtain body mass index (BMI) and nutritional status, interview using semi-quantitative food frequency questionnaire (FFQ) for consumption frequency of sugar-sweetened beverages and repeated 24 hour recall $3 \times 24$ hours to get data on carbohydrate, fat and protein intake. Then a blood sample is taken to obtain serum triglyceride levels. Medical Ethics Committee of Universitas Indonesia has approved the study protocol, and 47 subjects as the minimal sample size for a correlation study with an assumption of 0.4 as correlation coefficient value, had finished the study protocol.

\section{Measurements}

Data collection was carried out from April 2018 to May 2018. The data collected consisted of subject characteristics, weight, height, macro nutrient intake, consumption frequency of sugar-sweetened beverages and blood samples for examination of serum triglyceride levels. Body weight is measured by SECA 875 electrodigital scale. Height was measured by ShorrBoard from USA. From measurements of body weight and height then the body mass index is calculated then plotted in the BMI-for-age WHO curve to obtain nutritional 
status. Intake of macro nutrients was measured using food recall and then analyzed with Nutrisurvey software 2007 with an additional database of Indonesian food and then converted as carbohydrate, protein and fat intake. Serum triglyceride levels were measured using enzymatic colorimetric with glycerol-3-phosphate-oxidase (GPO) method.

\section{Statistical}

Data were analyzed with Shapiro-Wilk test to check the normality distribution of each data. Pearson correlation test was used to analyze the correlations between consumption frequency of sugar-sweetened beverages and serum triglyceride levels variables by using SPSS statistical software version 20 for Windows operating system.

\section{Results}

The result of this study showed the middle value age of the subjects are 16 years. BMI data were obtained through measurement of body weight and height. BMI measurements were used to determine the nutritional status of the subject. The nutritional status of the subjects was determined using the BMIfor-age curve from WHO 2005. Through normality tests on BMI it was found that BMI data were not normally distributed and presented in the form of middle values, minimum values and maximum values. In this study, the median of the subject BMI was at $20.9 \mathrm{~kg} / \mathrm{m} 2$ and for nutritional status around $1.4 \%$ of subjects were obese, $16.4 \%$ were overweight, $61.7 \%$ were normal, $4.3 \%$ were lean, and $6.4 \%$ were very thin (Table 1 ).

Table 1. Characteristics of subjects based on age, BMI, and nutritional status $(\mathrm{n}=47)$

\begin{tabular}{lc}
\hline \multicolumn{1}{c}{ Characteristics } & Results \\
\hline Age $($ years $)$ & $16(15-17)^{* *}$ \\
BMI $\left(\mathrm{kg} / \mathrm{m}^{2}\right)$ & $20.9(13.8-41.5)^{* *}$ \\
Nutritional status $\mathrm{n}(\%)$ & \\
Very thin & $3(6.4)$ \\
Lean & $2(4.3)$ \\
Normal & $29(61.7)$ \\
Overweight & $12(26.2)$ \\
Obese & $1(1.4)$ \\
\hline *mean \pm standart deviation;**median (minimum-maximum)
\end{tabular}

Table 2 shows the middle value for carbohydrate intake for the total study subjects was 155.4 grams per day and $87.2 \%$ of subjects have a carbohydrate intake below than $80 \%$ of the Recommended Dietary Allowance (RDA). In this study the total protein intake was 38.9 grams per day and $76.6 \%$ of the subjects had a protein intake below than $80 \%$ of the RDA. From the results of fat intake, it was found that the middle value of total fat intake was 45.5 grams per day, and $85.1 \%$ of subjects with fat intake below than $80 \%$ RDA. The average consumption frequency of sugar-sweetened beverages was 8.91 times per week and triglyceride levels was 110.49 $\mathrm{mg} / \mathrm{dL}$.

The results of the Pearson correlation test showed a significant positive correlation with very strong degrees $(p=<0.001, r=0.88)$ between the consumption frequency of sugar-sweetened beverages and serum triglyceride levels. Figure 1 shows the scatter plot for correlation between consumption frequency of sugar-sweetened beverages an triglyceride levels. The regression equation is $Y=41,236+7,768 X$

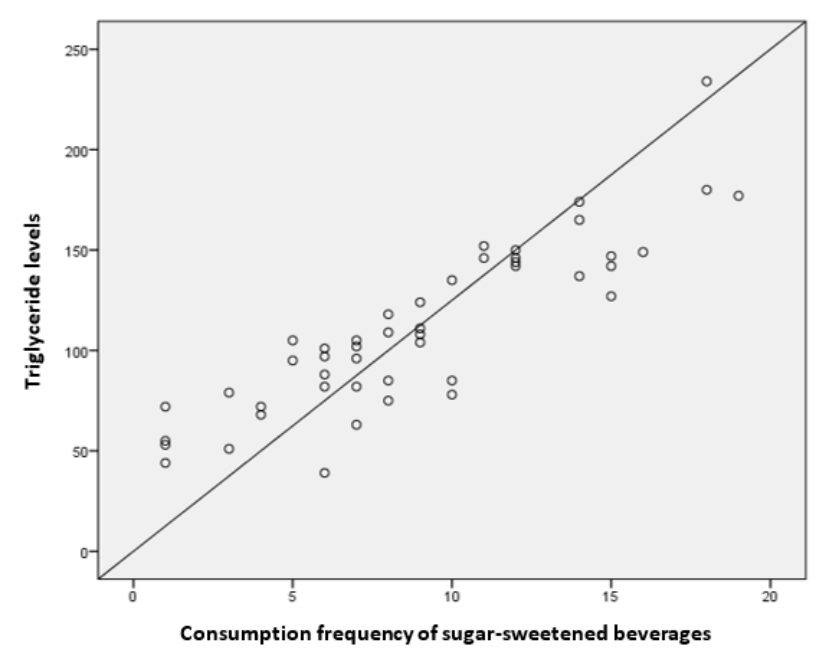

Figure 1 Scatter plot for correlation between consumption frequency of sugar-sweetened beverages an triglyceride levels

\section{Discussion}

To our knowledge, this is the first study in Indonesia to investigate the correlation between consumption frequency of sugar-sweetened beverages and serum triglyceride levels in female adolescence. The age 
range and sex of the subjects in this study are in line with the results of a study from Guelinckx et al, in which groups groups of female adolescence who consumed more soft drinks compared to male adolescence groups. ${ }^{13}$ In this study we found that $16.7 \%$ of subjects were overweight. This result is in line with data in Depok, namely adolescents aged $13-15$ years who are overweight at $12.1 \%$ and for the age group adolescents 16-18 years of age who are overweight are $17.0 \% .^{1}$ The macro nutrient intake of the subjects in this study was less than the RDA because the subjects reported less than what was actually consumed the rare group and those who did not consume sugarsweetened beverages at all. ${ }^{12}$

There are some limitations in this study: this study is a cross-sectional study where it cannot infer the temporal association between a risk factor and the outcome and the researchers did not analyze additional sugar levels in sugar-sweetened beverages consumed. This additional sugar level can illustrate how much extra sugar from soft drinks that contribute to the daily intake of individuals. In conclusion there was a significant positive correlation with very strong degrees between the consumption frequency of sugar-sweetened

Table 2 Characteristic of subjects based on intake of carbohydrates, fats, proteins, consumption frequency of sugar-sweetened beverages, and serum triglyceride levels $(n=47)$

\begin{tabular}{|c|c|}
\hline Characteristics & Results \\
\hline Carbohydrates intake per day $(\mathrm{g})$ & $155.4(60.8-342.7)^{* *}$ \\
\hline Carbohydrates intake to RDA (\%) & $53.2(20.8-117.4) * *$ \\
\hline Low (<80\% RDA), n(\%) & $41(87.2)$ \\
\hline Adequate (80-120\% RDA), n(\%) & $6(12.8)$ \\
\hline $\operatorname{High}(>120 \%$ RDA $), n(\%)$ & $0(0)$ \\
\hline Protein intake per day $(\mathrm{g})$ & $38.9(16.6-140.2)^{* *}$ \\
\hline Protein intake to RDA (\%) & $60.7(28-237)^{* *}$ \\
\hline Low $(<80 \%$ RDA $), n(\%)$ & $36(76.6)$ \\
\hline Adequate (80-120\% RDA), n(\%) & $9(19.1)$ \\
\hline $\operatorname{High}(>120 \%$ RDA $), n(\%)$ & $2(4.3)$ \\
\hline Fat intake per day $(\mathrm{g})$ & $45.5(13.5-133.6)^{* *}$ \\
\hline Fat intake to RDA (\%) & $64.1(19-188)^{* *}$ \\
\hline Low $(<80 \%$ RDA $), n(\%)$ & $40(85.1)$ \\
\hline Adequate (80-120\% RDA), n(\%) & $5(10.6)$ \\
\hline $\operatorname{High}(>120 \%$ RDA $), n(\%)$ & $2(4.3)$ \\
\hline $\begin{array}{l}\text { Consumption frequency of sugar-sweetened beverages } \\
\text { (times/week) }\end{array}$ & $8.91 \pm 4.71 *$ \\
\hline Serum triglyceride levels $(\mathrm{mg} / \mathrm{dL})$ & $110.49 \pm 41.49 *$ \\
\hline
\end{tabular}

*mean \pm standart deviation; **median (minimum-maximum)

This study found a significant positive correlation with very strong degrees $(p=<0.001$, $\mathrm{r}=0.88$ ) between the consumption frequency of sugar-sweetened beverages and serum triglyceride levels. The results of this study are in line with Van Rompay et al study which states that in children and adolescents who consumed sweetened soft drinks more than once a week increased their triglyceride levels higher about $7.9 \mathrm{mg} / \mathrm{dL}$ compared to those who consumed less frequently. ${ }^{11}$ Other studies that conducted by Kosova et al. in children aged 9-11 years also stated the same thing, namely the female sex group that often consumed sugar-sweetened beverages had higher triglyceride levels compared to beverages and serum triglyceride levels. Thus, the present findings can be regarded as a small step forward for other researchers to research further, for example, doing an intervention study about sugarsweetened beverages.

\section{Conflict of Interest}

None of the other authors have conflict of interest. No educational grant is provided to the rest of authors.

\section{Open Access}


This article is distributed under the terms of the Creative Commons Attribution 4.0 International Licence(http://creativecommons.org/licenses/by/4.0 /), which permits unrestricted use, distribution, and reproduction in any medium, provided you give appropriate credit to the original author(s) and the source, provide a link to the Creative Commons license, and indicate if changes were made.

\section{References}

1. Kementerian Kesehatan RI. Badan Penelitian Dan Pengembangan Kesehatan Kementerian RI Riset Kesehatan Dasar 2013. Jakarta; 2013.

2. Preedy V. Dietery Sugars; Chemistry, Analysis, Function, and Effect. Cambridge: Royal Society of Chemistry; 2012. [Google Scholar]

3. Bleich SN, Vercammen KA. The negative impact of sugar-sweetened beverages on children's health: An update of the literature. BMC obesity 2018;5(1):6. [Google Scholar]

4. Sánchez-Pimienta TG, Batis C, Lutter CK, Rivera JA. Sugar-Sweetened Beverages Are the Main Sources of Added Sugar Intake in the Mexican Population-5. The Journal of nutrition. 2016 Aug 10;146(9):1888S-96S.

5. Bel-Serrat S, Mouratidou T, Huybrechts I, et al. Associations between macronutrient intake and serum lipid profile depend on body fat in European adolescents: The Healthy Lifestyle in Europe by Nutrition in Adolescence (HELENA) study. Br J Nutr 2014;112(12):2049-2059. doi: 10.1017/S0007114514003183.] [Google Scholar]

6. Magnussen CG, Raitakari OT, Thomson R, et al. Utility of currently recommended pediatric dyslipidemia classifications in predicting dyslipidemia in adulthood: Evidence from the childhood determinants of adult health (CDAH) study, cardiovascular risk in Young Finns study, and Bogalusa heart study. Circulation 2008;117(1):32-42. doi: 10.1161/CIRCULATIONAHA.107.718981. [Google Scholar]

7. Harrington S. The role of sugar-sweetened beverage consumption in adolescent obesity: a review of the literature. J Sch Nurs 2008;24(1):3-12. doi: 10.1622/10598405(2008)024[0003:TROSBC]2.0.CO;2. [Google Scholar]

8. Malik VS, Schulze MB, Hu FB. Intake of sugar-sweetened beverages and weight gain: A systematic review. Am J Clin Nutr 2006;84(2):274-288. doi: 84/2/274. [Google Scholar]

9. McGregor RA, Choi MS. microRNAs in the Regulation of Adipogenesis and Obesity. Curr Mol Med 2011;11(4):304-316. doi: 10.2174/156652411795677990. [Google Scholar]

10. Nelms M, Sucher K, Lacey K, Roth S. Nutrition Therapy \& Pathophysiology. J Chem Inf Model. 2013;53.

11. Rompay, M. Van, McKeown N, Eliasziw M, et al. Intakes of sugar-sweetened beverages and total sugars are associated with higher triglycerides in a multi-ethnic sample of children. Circulation 2015;145:2389. [Google Scholar]

12. Kosova EC, Auinger P, Bremer AA. The Relationships between Sugar-Sweetened Beverage Intake and Cardiometabolic Markers in Young Children. J Acad Nutr Diet 2013;113(2):219-227. doi: 10.1016/j.jand.2012.10.020. [Google Scholar]

13. Guelinckx I, Iglesia I, Bottin JH, et al. Intake of water and beverages of children and adolescents in 13 countries. Eur J Nutr 2015;54:69-79. doi: 10.1007/s00394-0150955-5. [Google Scholar] 